\title{
The Application of Industry 4.0 in Customized Furniture Manufacturing Industry
}

\author{
Lin Wang ${ }^{1, *}$, Jinfeng $\mathrm{He}^{2}$ and Songjie $\mathrm{Xu}^{2}$ \\ ${ }^{1}$ School of Management Engineering, Zhengzhou University, Zhengzhou, China \\ ${ }^{2}$ School of Management Engineering, Henan Institute of Engineering, Zhengzhou, China
}

\begin{abstract}
In the background of industrial 4.0, this paper analyzes the developmental road about customized furniture factory. Based on the concepts and features of industry 4.0 , this paper analyzes the composition of the customized furniture factory, the main operation system and the operation process of the intelligent customized furniture factory. In order to achieve efficient and accurate production targets, intelligent customized furniture factory should be set up through the establishment of cyber physical system( CPS) to cover the intelligent network.
\end{abstract}

\section{Introduction}

At present, the traditional furniture manufacturing industry is facing with a challenge. It is becoming easier for people to obtain the necessary information. Consumers are looking for customized products and services. In order to meet people's living needs, Germany put forward the concept of "Industry 4.0". The Chinese government developed the concept of "China Made 2025" in 2015. At the same time, "Industrial Internet" is proposed by the United States in 2009. They all aim at transforming the traditional industries through the Internet [1]. Through the use of "Things of internet "and" business networking (service Internet)", traditional industries can achieve flexible production, zero inventory and Internet marketing. As a traditional manufacturing industry, furniture industry based on a solid industrial base. So it should learn the strategic thinking of industrial 4.0, and explore the "manufacturing + Internet" actively.

\section{Industrial 4.0 concept and features}

\subsection{The concept of industry 4.0}

Based on the CPS, industrial 4.0 can realize the timely communication, recognition between people by building up a highly flexible and intelligent manufacturing mode [2]. Industrial 4.0 is the fourth industrial revolution led by intelligent manufacturing. It aims at transforming the manufacturing industry into an intelligent one by the combination of information communication technology, cyberspace virtual system and cyber physical system (CPS).

\subsection{Industrial 4.0 features}

\subsubsection{Interconnection}

The interconnection between devices is the core content of "Industry 4.0". For example, interconnection between all kinds of equipment which have different functions is composed intelligent workshops and factories. Interconnection between equipment and products refers to that they can communicate by a special language. By reading the product information, equipment can achieve intelligent production. Cyber Physical System(CPS) can realize the integration of network world and physical world by connecting the single intelligent device with the internet. In this way, these intelligent devices can achieve self-adapting, self-diagnosing, self-repairing and remote assistance[3].

\subsubsection{Integration}

Through the physical information system ,"Industrial 4.0" can combine production system sensors, control systems, production equipment together to form an intelligent network. The goal of vertical integration is to realize seamless connection of product information, such as product design, manufacturing, logistics, transportation and maintenance. 


\subsubsection{Big Data}

During the production process, the intelligent manufacturing equipment will produce a large number of productionrelated information and data. We need to collect the data information and give feedback to all aspects of production. In this way, we can achieve efficient high-quality operation process[4].

\section{The Application of Industrial 4.0 in customized furniture factory}

Furniture is closely related to people's life. But the increasingly cost, excess capacity and customized market all require a high degree of automation, intelligence, flexibility of the direction. The requirements mentioned above are in accordance with the requirements of the custom furniture factory.

\subsection{Intelligent factory}

Intelligent plant connect the intelligent physical devices by industrial internet intelligent physical devices. Intelligent devices can do computing, communication, precise control, remote assistance and autonomy[5]. In the future, firstly we need obtain the customer's customized information. Then the virtual factory which based on cloud based design and manufacturing will do the design and simulation. Finally, customer confirmed the product and the computer integrate and send the appropriate data to the appropriate equipment. Intelligent devices can read each other tags to achieve the information transfer function. Based on the information, intelligent devices can complete the manufacturing, testing and other activities.

The intelligent factory is the data-based enterprise. The daily operation of the intelligent factory mainly depends on following software and hardware: the industry thing networking, the industry network security, the industry big data, the cloud computation platform, the MES system, the virtual reality, RFID, 3D printing, machine vision, intelligent logistics and so on. The hardware includes industrial robots, data acquisition, industrial switches[6].

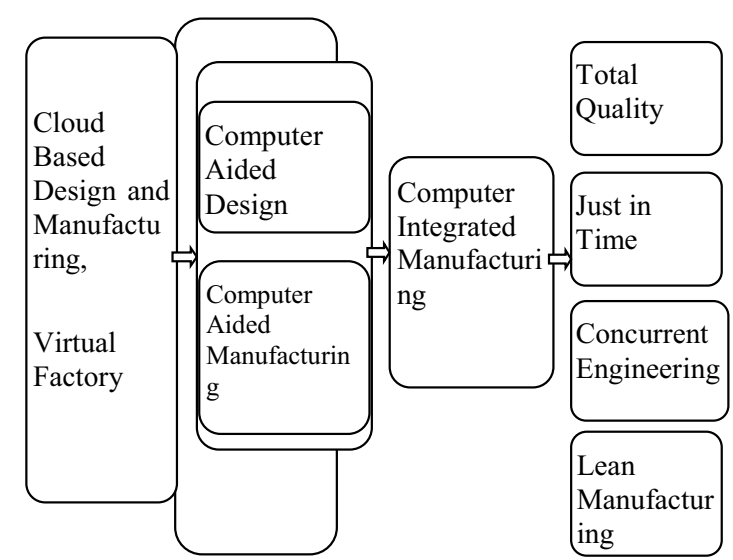

Fig. 1. Main operating activities of intelligent furniture factory

\subsection{The main operating network system}

The intelligent custom furniture factory uses information communication technology(ICT) and cyber physical system (CPS) to link related equipment, production lines, factories, related parties and products together. The entire intelligent network is divided into two parts. The information transmission in the custom-made furniture factory is called M2M. It transforms dialogue among human and machine. Factory exchange information through the Internet of Things which includes the factory's payment platform, intelligent logistics platform, and design platform to finish production. The process shows in Figure 2. 


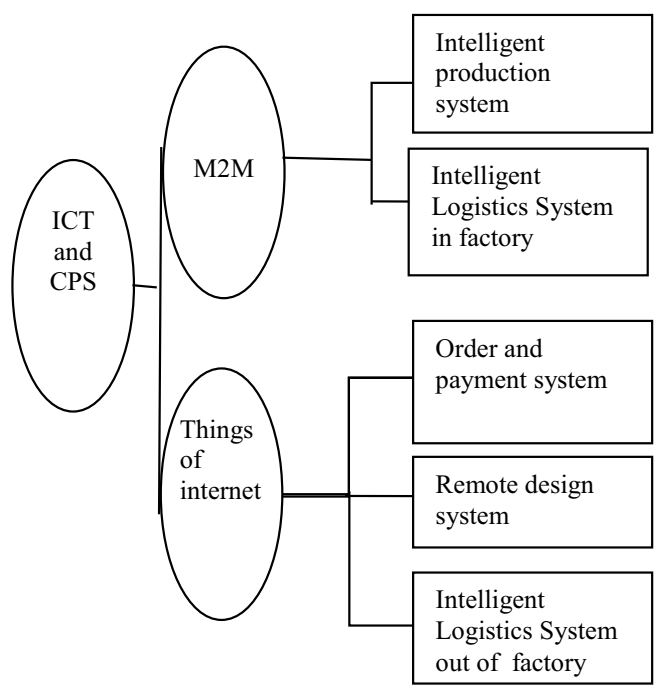

Fig2 Intelligent network and main operating system of intelligent furniture factory

\subsection{Main operating system}

Intelligent custom furniture factory is composed by an intelligent production line and network (financial enterprises, product design institute, production equipment factory, technical personnel training institutions, raw material suppliers, logistics companies, etc.). The intelligent operation system of the intelligent customized furniture factory can be divided into payment system, remote product development and design system, intelligent production system and intelligent logistics system.

1) Intelligent order and payment system. Through the system's intelligent ordering platform, the factory can accept the orders made by external factory. After the approval, the orders will be revised or negotiated according to order requirements.

2) Remote product development and design system. When receiving new products or customized product orders, they need to design products by computer simulation. The computer can set up three-dimensional model in accordance with the real work of the operation.

Then the product can be displayed on the screen.According to the views of customers, the designer will modify the model and print out new products to customers by the 3D printer.

3) Intelligent production system. Intelligent production system is the main system of intelligent machinery plant, involving the entire factory production processes, machinery, equipment and plant logistics management. In the intelligent factory, every part of the product blank, spare parts, tools, transport boxes, machines are equipped with sensors.

4) Intelligent logistics system. The intelligent logistics system is a modern logistics system which is composed by bar code, radio frequency identification technology, sensors, global positioning system and so on. Through the intelligent network formed by CPS, the logistics resources integrate and operate in the electronic commerce way. First of all, we collect the relevant data.Based on the data, we analyze and build the model. Then we establish intelligent logistics base database; Finally, we enhance the customer management and business process optimization.

\subsection{Operation process}

Through the cyber physical system(CPS) and the internet of things, the Semi-finished products are sent to the processing plant and workstation to arrange production process. Finally, they send product to custom by modern logistics.

Intelligent machinery plant operating process shown in Figure3. 


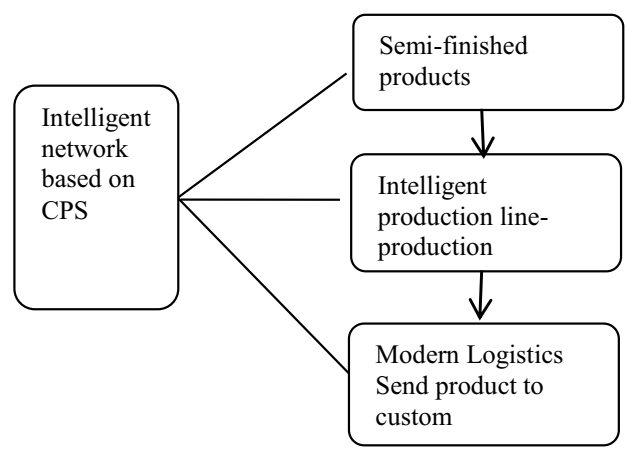

Figure 3 Operation flow of intelligent machinery plant

\section{Conclusion}

Because the furniture manufacturing industry is faced with many problems, such as low efficiency of resource use, great pressure of environment, high labor cost.The intelligent manufacturing is the inevitable trend of the future furniture manufacturing industry. "Industrial 4.0 " has the advantages, such as high efficiency of resource allocation, quick response to market demand, low labor cost and logistics cost. In this way, we can apply "Industrial 4.0" into customized furniture manufacturing industry. With the poor foundation and high-tech backwardness, China's furniture manufacturing industry still face challenges. We should make full use of its huge customer market to catch up with the steps of industry automation, intelligence and green trend.

\section{References}

1. Zhihui, Wu. Manufacturing Model of Furniture Industry in Industry 4.0. China forest products industry, 2016, 43(3): 7-7

2. Jian, Li. Made in China by 2025, the German Industrial 4.0, Industrial Internet Strategy of the United States and China Plastic Machinery. Plastics Technology and Equipment, 2015(21):3-6.

3. Zuehlke D. Smart Factory Towards a factory of things. Annual Reviews in control, 2010(34):129-138

4. Hongmin, Dai. 4.0 Industrial and Intelligent Machinery Plant. Packaging engineering, 2016, 37(19): 208-209

5. Jun, Yin. The application of industry 4.0 in aeronautical manufacturing industry. Manufacturing Automation, 2015, 37 (10): $5-5$

6. Shu, Zhang. The Industry 4. 0 and Intelligent Manufacturing. Machine Design and Manufacturing Engineering, 2014, 43(8): 4-4 